Article

\title{
Interplay between OmpA and RpoN Regulates Flagellar Synthesis in Stenotrophomonas maltophilia
}

\author{
Chun-Hsing Liao ${ }^{1,2,+}$, Chia-Lun Chang ${ }^{3,+}$, Hsin-Hui Huang ${ }^{3}$, Yi-Tsung Lin ${ }^{2,4}$, Li-Hua Li ${ }^{5,6}$ \\ and Tsuey-Ching Yang ${ }^{3, *}$
}

1 Division of Infectious Disease, Far Eastern Memorial Hospital, New Taipei City 220, Taiwan; liaochunhsing@gmail.com

2 Department of Medicine, National Yang Ming Chiao Tung University, Taipei 112, Taiwan; ytlin8@vghtpe.gov.tw

3 Department of Biotechnology and Laboratory Science in Medicine, National Yang Ming Chiao Tung University, Taipei 112, Taiwan; kartd0087603@gmail.com (C.-L.C.); toe3273917@outlook.com (H.-H.H.)

4 Division of Infectious Diseases, Department of Medicine, Taipei Veterans General Hospital, Taipei 112, Taiwan

5 Department of Pathology and Laboratory Medicine, Taipei Veterans General Hosiptal, Taipei 112, Taiwan; lilh@vghtpe.gov.tw

6 Ph.D. Program in Medical Biotechnology, Taipei Medical University, Taipei 110, Taiwan

* Correspondence: tcyang@nycu.edu.tw

+ Liao, C.-H. and Chang, C.-L. contributed equally to this work.

Citation: Liao, C.-H.; Chang, C.-L.; Huang, H.-H.; Lin, Y.-T.; Li, L.-H.; Yang, T.-C. Interplay between OmpA and RpoN Regulates Flagellar Synthesis in Stenotrophomonas maltophilia. Microorganisms 2021, 9, 1216. https://doi.org/10.3390/ microorganisms 9061216

Academic Editor: Paolo Visca

Received: 21 April 2021

Accepted: 2 June 2021

Published: 4 June 2021

Publisher's Note: MDPI stays neutral with regard to jurisdictional claims in published maps and institutional affiliations.

Copyright: (c) 2021 by the authors. Licensee MDPI, Basel, Switzerland. This article is an open access article distributed under the terms and conditions of the Creative Commons Attribution (CC BY) license (https:/ / creativecommons.org/licenses/by/ $4.0 /)$.

\begin{abstract}
OmpA, which encodes outer membrane protein A (OmpA), is the most abundant transcript in Stenotrophomonas maltophilia based on transcriptome analyses. The functions of OmpA, including adhesion, biofilm formation, drug resistance, and immune response targets, have been reported in some microorganisms, but few functions are known in S. maltophilia. This study aimed to elucidate the relationship between OmpA and swimming motility in S. maltophilia. KJ $\Delta \mathrm{OmpA}$, an ompA mutant, displayed compromised swimming and failure of conjugation-mediated plasmid transportation. The hierarchical organization of flagella synthesis genes in S. maltophilia was established by referencing the Pseudomonas aeruginosa model and was confirmed using mutant construction, qRT-PCR, and functional assays. Distinct from the P. aeruginosa model, rpoN, rather than fleQ and fliA, was at the top of the flagellar regulatory cascade in $S$. maltophilia. To elucidate the underlying mechanism responsible for $\triangle o m p A$-mediated swimming compromise, transcriptome analysis of $\mathrm{KJ}$ and $\mathrm{KJ} \Delta \mathrm{OmpA}$ was performed and revealed $r p o N$ downregulation in $\mathrm{KJ} \Delta \mathrm{OmpA}$ as the key element. The involvement of rpoN in $\triangle o m p A$-mediated swimming compromise was verified using rpoN complementation, qRTPCR, and function assays. Collectively, OmpA, which contributes to bacterial conjugation and swimming, is a promising target for adjuvant design in S. maltophilia.
\end{abstract}

Keywords: Stenotrophomonas maltophilia; OmpA; swimming; flagellum

\section{Introduction}

Gram-negative bacteria are surrounded by two membranes, which confine the periplasmic space containing the peptidoglycan [1]. This double membrane may be impenetrable to antibiotics, noxious agents, or other foreign compounds [2,3]. The outer membrane $(\mathrm{OM})$ is a complex organelle that provides a barrier to protect bacteria from hazards in their environment. The OM of Gram-negative bacteria is unique in its composition and shows asymmetrical lipid distribution. Approximately 50\% of the OM mass consists of proteins, either integral membrane proteins or membrane-anchored lipoproteins. Thus, as much as 3\% of the Gram-negative bacterial genome may encode outer membrane proteins (OMPs) [4]. Nearly all of the integral membrane proteins of the OM assume a $\beta$-barrel architecture with long loops between the strands on the extracellular side and short loops on the periplasmic side. $\beta$-barrel OMPs are classified into two major types, classical porins and slow porins, based on their physiological roles. Classical porins serve as ports of 
entry for hydrophilic molecules in a non-selective fashion, facilitating the diffusion of nutrients and extrusion of waste products [5]. OmpF and OmpC are the most studied classical porins in Gram-negative bacteria and are highly conserved throughout the Enterobacterales [6,7]. In contrast, slow porins have very low permeability, and molecular transportation is not their main function. Escherichia coli OmpA, Acinetobacter baumannii OmpA, and Pseudomonas aeruginosa OprF are examples of slow porins. OmpA is a surfaceexposed porin protein with a high copy number among the OMPs of E. coli [8]. Its Nterminal domain comprises eight transmembrane antiparallel $\beta$-strands, and its $\mathrm{C}$-terminal domain interacts with the peptidoglycan layer $[9,10]$. OmpA is involved in adhesion, invasion, biofilm formation, drug resistance, and bacteriophage entry [11-14]. In addition, OmpA acts as an immune target and induces host immune responses [15,16]; thus, it is the most popular vaccine candidate widely developed in E. coli, Klebsiella pneumoniae, and A. baumannii [17-19].

Swimming motility is a critical aspect of bacterial pathogenesis and is required for host colonization. It is also crucial for many biological functions including nutrient acquisition, stress avoidance, and sexual reproduction $[20,21]$. The flagellum is the most important organelle for bacterial swimming. It is composed of a basal body, hook, and a long, thin filament. The basal body, consisting of rotors and a stator, is embedded in the bacterial membrane. The hook is a joint that connects the basal body and filament. Flagellin is the subunit protein of the filament, which is a whip-like appendage that enables bacterial motility. Bacterial flagellum assembly requires the expression of nearly 60 genes in multiple operons, which are clustered at several loci on the chromosome [22]. Studies on flagellum synthesis have been carried out in several bacteria, including E. coli, Salmonella typhimurium [23], Caulobacter crescentus [24], Vibrio cholerae [25], V. parahaemolyticuss [26], and P. aeruginosa [27]. Flagellum synthesis has been hierarchically organized. A transcription of flagellum synthesis genes forms an ordered cascade whereby a gene located at a higher level must first be expressed before that of the next level. In the hierarchical cascade, several checkpoints are set to ensure that flagellar components are expressed and assembled sequentially. Flagellum synthesis is hierarchically regulated at three levels in E. coli [28] and is hierarchically classified into four classes in C. crescentus [24], V. cholerae [25], and P. aeruginosa [27]. In addition to a functional flagellum, effective swimming relies on the bacterial repertoire for sensing environmental conditions. Thus, a pathogen generally harbors several efficient signaling systems to sense environmental stimuli or quorum sensing (QS) signals, direct their movement to attractants, and avoid repellents.

Stenotrophomonas maltophilia, widely distributed in nature and in hospitals, has emerged as a global opportunistic Gram-negative pathogen, especially in patients with cystic fibrosis and immunocompromised individuals [29]. S. maltophilia is considered to be a low-virulence pathogen; however, the treatment of an S. maltophilia infection is a major challenge due to its intrinsic resistance to several antibiotics that are commonly used in clinics [30]. The reported resistance mechanisms in S. maltophilia include poor membrane permeability, antibiotic hydrolysis or modification, and efflux pump overexpression [31]. Thus, it is increasingly challenging for physicians to use conventional therapies to effectively treat S. maltophilia infections [32]. Novel convincing targets in S. maltophilia are greatly needed for the development of antibiotics, adjuvants, and even vaccines. Transcriptome analysis of $S$. maltophilia $\mathrm{KJ}$ was performed in our recent study, and the results demonstrated that ompA (Smlt0955) has the greatest transcript abundance in logarithmically grown KJ cells [33]. Given our understanding of OmpA in other Gram-negative bacteria, the OmpA of S. maltophilia is a prospective candidate to be first considered for the development of antibiotics, adjuvants, or vaccines. However, the current understanding of OmpA in S. maltophilia is relatively deficient, except for the reports by Li et al. that focused on the immunogenic properties of OmpA and the host protective immune response [34,35]. Given that OmpA is the most abundant OMP in S. maltophilia, it should be a critical contributor to the maintenance of membrane integrity. Bacterial membrane integrity has a significant impact on flagellum assembly and swimming motility. In this study, the link 
between OmpA and swimming motility in S. maltophilia was investigated. We revealed that the deletion of ompA resulted in swimming compromise and thus conducted experiments aimed at elucidating the underlying molecular mechanism.

\section{Materials and Methods}

\subsection{Bacterial Strains, Media, Plasmids, and Primers}

The bacterial strains, plasmids, and primers used in this study are listed in Table S1. S. mlatophilia KJ was an isolate isolated from sputum and identified using the Phoenix ${ }^{\mathrm{TM}} 100$ system (Becton Dickinson).

\subsection{Construction of in-Frame Deletion Mutants}

The in-frame deletion mutants were constructed using double cross-over homologous recombination. The DNA fragments flanking the deleted genes were amplified using PCR and subsequently cloned into pEX18Tc to generate the mutagenic plasmids. The primers set for the construction of mutagenic plasmids were OmpAN-F/OmpAN-R and OmpAC-F/OmpAC-R for $\mathrm{p} \Delta \mathrm{OmpA}$, FliC1N-F/FliC1N-R and FliC3C-F/FliC3C-R for $\mathrm{p} \Delta$ FliC1C2C3, RpoNN-F/RpoNN-R and RpoNC-F/RpoNC-R for $\mathrm{p} \Delta \mathrm{RpoN}$, FleQNF/FleQN-R and FleQC-F/FleQC-R for $\mathrm{p} \Delta$ FleQ, as well as FliAN-F/FliAN-R and FliAC$\mathrm{F} /$ FliAC-R for $\mathrm{p} \Delta$ FliA (Table S1). Mutagenic plasmids were transferred into S. maltophilia by conjugation. The plasmid's conjugation, transconjugant's selection, and mutant's confirmation were carried out as described previously [36].

\subsection{Construction of KJL2::OmpA $\triangle O m p A$ and KJL2::RpoN $\triangle O m p A$}

As plasmid transportation by conjugation is unavailable in the ompA mutant (KJ $\Delta \mathrm{OmpA}$ ), an alternative strategy was designed for gene expression in $\mathrm{KJ} \Delta \mathrm{OmpA}$. First, the gene intended to be expressed in $\mathrm{KJ} \Delta \mathrm{OmpA}$ was chromosomally replaced with the L2 gene using double cross-over homologous recombination; the prototype chromosomal ompA gene was then deleted. For this purpose, we first constructed a recombinant plasmid, pEXCJ1. The 353-bp and 376-bp DNA fragments upstream and downstream of the L2 gene were obtained by PCR using primers pEXCJ1N-F/pEXCJ1N-R and pEXCJ1C-F/pEXCJ1C$\mathrm{R}$ (Table S1), respectively, and were subsequently cloned into pEX18Tc to yield pEXCJ1. The multiple cloning sites (SphI/PstI/SalI/XbaI/BamHI/SmaI/KpnI/SacI) of pEX18Tc were used for cloning the exotic gene intended to be expressed in KJ $\Delta \mathrm{OmpA}$.

The intact $o m p A$ and $r p o N$ genes were amplified by PCR using the primer sets OmpA-F/OmpA-R and RpoN-F/RpoN-R (Table S1), respectively, and were then cloned into pEXCJ1 to yield pCJ1-OmpA and pCJ1-RpoN. The plasmids pCJ1-OmpA and pCJ1RpoN were transferred into $S$. maltophilia KJ to generate KJL2::OmpA and KJL2::RpoN, respectively. The prototype chromosomal ompA gene was deleted from KJL2::OmpA and KJL2::RpoN to yield KJL2::OmpA $\Delta \mathrm{OmpA}$ and KJL2::RpoN $\Delta \mathrm{OmpA}$, respectively.

\subsection{Construction of $P_{r p o N^{-} x y l E}$ Transcription Fusion Plasmid, $p R p o N_{x y l E}$}

The 576-bp DNA fragment upstream of the rpoN gene was obtained by PCR using primer sets RpoNN-F/RpoNN-R (Table S1) and cloned into pRKxylE, a $x y l E$ reporter

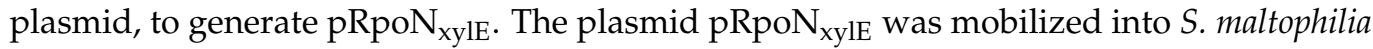
strains indicated for a promoter activity assay.

\subsection{OMP Preparation and SDS-PAGE}

Logarithmic-phase cells were harvested and OMPs were prepared using the $N$-lauroylsarcosine method described previously [37]. The purified OMPs were boiled for $5 \mathrm{~min}$ at $100{ }^{\circ} \mathrm{C}$ and then separated using SDS-PAGE electrophoresis in a $15 \%$ polyacrylamide gel. The gel was stained with $0.1 \%$ Coomassie brilliant blue R250 (Bio-Rad) and de-stained with $40 \%$ methanol $/ 10 \%$ glacial acetic acid for the visualization of proteins. 


\subsection{Catechol 2,3-Dioxygenase (C23O) Activity Assay}

Catechol-2,3-dioxygenase is encoded by the $x y l E$ gene, and its activity was measured using $100 \mathrm{mM}$ catechol as the substrate, as described previously [38]. The hydrolysis rate of catechol was calculated using $44,000 \mathrm{M}^{-1} \mathrm{~cm}^{-1}$ as the extinction coefficient. One unit of enzyme activity $(\mathrm{U})$ was defined as the amount of enzyme that converts 1 nmole of substrate per minute. The specific activity was expressed as $\mathrm{U} / \mathrm{OD}_{450} \mathrm{~nm}$.

\subsection{Swimming Assay}

Five $\mu \mathrm{L}$ of a logarithmically grown bacterial cell culture were inoculated onto the swimming agar ( $1 \%$ tryptone, $0.5 \% \mathrm{NaCl}$, and $0.15 \%$ agar). The plates were incubated at $37^{\circ} \mathrm{C}$ for $48 \mathrm{~h}$ and the diameters of the swimming zones $(\mathrm{mm})$ were recorded.

\subsection{Flagella Staining}

We analyzed the presence of flagella using negative staining with $1 \%$ phosphotungstic acid ( $\mathrm{pH}$ 7.4) and observed using transmission electron microscopy (TEM) (Hitachi H-7650 microscope), as described previously [39].

\subsection{Preparation of Polyclonal Anti-Rabbit Anti-FliC3 Antibody}

Of the three $\mathrm{fliC}$ homologue genes, fliC3 (Smlt2304) is annotated as fliC in the S. maltophilia K279a genome [40]; thus, it was selected as the candidate for the preparation of a polyclonal antibody. The full coding sequence of fliC 3 was amplified by PCR using the primer sets FliC3his-F and FliC3his-R (Table S1) and ligated to the vector pET-24b, yielding pETFliC3. For expression, the recombinant plasmid pETFliC 3 was transformed into E. coli BL21(DE3). The logarithmically grown E. coli BL21(DE3)(pETFliC3) cells were treated with $1 \mathrm{mM}$ IPTG for $3 \mathrm{~h}$ and the fusion proteins FliC3-6His were purified with Ni-NTA resin. Antibodies against the FliC3-6His protein were raised by the immunization of New Zealand rabbits with the purified FliC3-6His protein.

\subsection{SDS-PAGE and Western Blot Analysis}

The logarithmically grown bacterial cells were disrupted via sonication. Intracellular proteins were separated using electrophoresis in 15\% (w/v) SDS-PAGE, transferred onto polyvinylidene difluoride (PVDF) membranes, and probed with anti-FliC3 and anti-RpoA antibodies. The protein RpoA served as an intracellular control.

\subsection{Transcriptome Analysis}

Overnight cultures of $\mathrm{KJ}$ and $\mathrm{KJ} \Delta \mathrm{OmpA}$ were subcultured into fresh $\mathrm{LB}$ at an initial $\mathrm{OD}_{450} \mathrm{~nm}$ of 0.15 and incubated for $5 \mathrm{~h}$ to a logarithmic phase. Total RNA isolation, rRNA depletion, adapter-ligated cDNA library construction and enrichment, and cDNA sequencing were performed as described previously [41]. The sequencing reads were mapped to the S. maltophilia K279a genome. RNA-seq results were analyzed using a CLC Genomics Workbench v 6.0 (CLC Bio) and presented as Reads Per Kilobase per Million mapped reads (RPKM).

\subsection{Quantitative Reverse Transcription-PCR ( $q R T-P C R$ )}

DNA-free RNA for qRT-PCR was prepared from logarithmically grown bacterial cells, as described previously [42]. The primers used for the qRT-PCR of each gene are listed in Table S1. The relative transcription level was calculated using the comparative $C_{T}\left(\Delta \Delta C_{T}\right)$ method [43] and 16S rRNA was used as the endogenous control. Each result represents the average of three independent determinations. 


\section{Results}

\subsection{Bioinformatics Analysis of OmpA}

The transcriptome analysis of KJ cells in the logarithmic phase was performed in our recent study [33]. OmpA (Smlt0955) showed the greatest transcript abundance in wild-type $\mathrm{KJ}$ under our experimental conditions. The presence of any protein in such a large amount suggests that it may play a significant role in bacteria. Based on this, we investigated the functions of OmpA and proposed some innovative aspects for this OMP.

Omp $A$, encoding a 366-amino acid $\beta$-barrel OMP, is well conserved in all of the sequenced $S$. maltophilia genomes. BLAST analysis showed that OmpAs of S. maltophilia strains shared 86 to $99 \%$ protein identities. However, S. maltophilia OmpA showed relatively lower identity with its homologues in other bacterial species, such as $22 \%$ identity with the OmpA of E. coli and 32\% identity with the OprF of P. aeruginosa PAO1.

\subsection{OmpA Deletion Impairs Bacterial Conjugation}

To elucidate the function of OmpA in S. maltophilia, an in-frame deletion mutant of $\operatorname{mp} A, \mathrm{KJ} \Delta \mathrm{OmpA}$, was constructed by deleting the OmpA-like domain (amino acids 297-357) (Figure 1). A recombinant plasmid, pOmpA, containing an intact ompA gene was prepared for the complementary assay of $\mathrm{KJ} \Delta \mathrm{OmpA}$. Despite several attempts to introduce pOmpA back into $\mathrm{KJ} \Delta \mathrm{OmpA}$ by conjugation, no transconjugant was obtained. Our attempts to transfer the empty plasmid, pRK415, into $\mathrm{KJ} \Delta \mathrm{OmpA}$ by conjugation also failed. In contrast, the plasmid pOmpA was successfully transferred into wild-type KJ, yielding $\mathrm{KJ}(\mathrm{pOmpA})$. Collectively, the failure of the conjugation-mediated plasmid transfer appeared to originate from the lost OmpA function, implying that OmpA is a critical OMP for conjugation in S. maltophilia.

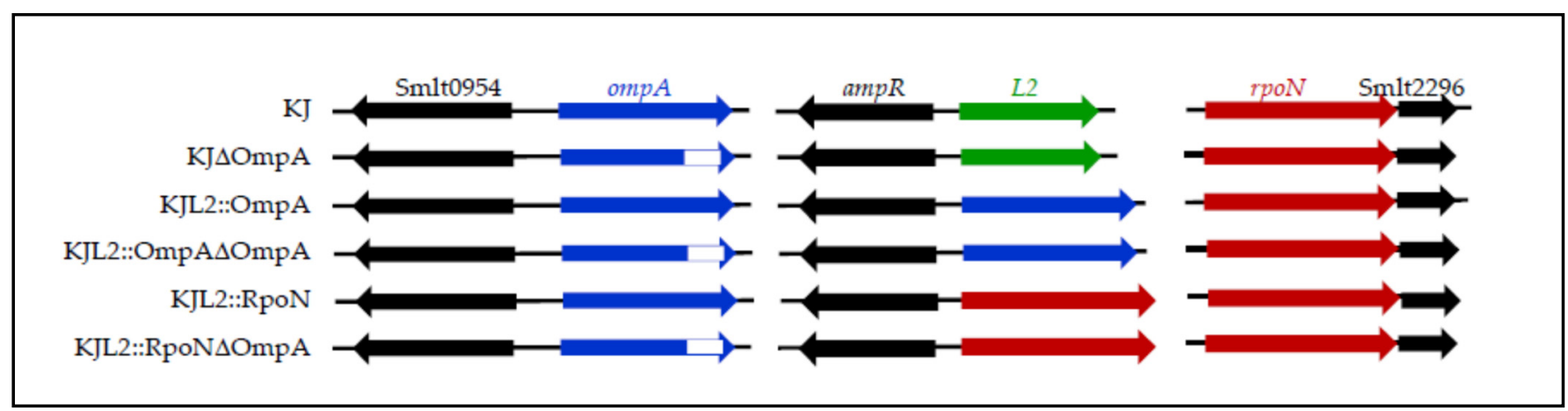

Figure 1. Genomic organization of $\mathrm{KJ}$ and its derived ompA-associated constructs. The orientation of the gene is indicated by the arrow. The white box indicates the deleted region of the ompA gene.

An alternative strategy was applied for the complementary assay. We first generated a conditional construct of $S$. maltophilia KJ, KJL2::OmpA, in which the chromosomal L2 gene was replaced with an intact ompA gene (Figure 1). Thus, in this construct, the ompA gene was driven by the $L 2$ promoter, $P_{L 2} . P_{L 2}$ has basal-level activity in the absence of $\beta$-lactam and can be upregulated upon $\beta$-lactam challenge [44]. Next, the prototype omp $A$ gene in KJL2::OmpA was deleted via a double cross-over homologous recombination to yield KJL2::OmpA $\Delta$ OmpA (Figure 1), which was regarded as an alternative complementary strain of the mutant KJ $\Delta \mathrm{OmpA}$. The OMP profiles of wild-type KJ, mutant KJ $\Delta \mathrm{OmpA}$, and the complementary strain KJL2::OmpA $\triangle O$ mpA were revealed using SDS-PAGE (Figure S1). Compared with wild-type $\mathrm{KJ}$, a band corresponding to $38 \mathrm{kDa}$ was absent in the $\mathrm{KJ} \Delta \mathrm{OmpA}$ protein profiles, but was visible in KJL2::OmpA $\Delta$ OmpA. The 38-kDa protein was verified as the OmpA protein using LC-MS/MS. 


\subsection{OmpA Deletion Attenuates Swimming Motility}

The growth curves of wild-type $\mathrm{KJ}, \mathrm{KJ} \Delta \mathrm{OmpA}$, and KJL2::OmpA $\Delta \mathrm{OmpA}$ were determined during a period of $24 \mathrm{~h}$, and were found to be undistinguishable. This indicated that ompA inactivation had no obvious effect on bacterial growth.

Given that OmpA is the most abundant transcript revealed using transcriptome analysis, envelope integrity may be compromised in an OmpA protein-null mutant. An intact envelope is a prerequisite for flagellar assembly and swimming motility; thus, we were interested in understanding the impact of ompA deletion on swimming motility. The swimming motilities of $\mathrm{KJ}, \mathrm{KJ} \Delta \mathrm{OmpA}$, and $\mathrm{KJ} \mathrm{L} 2:: \mathrm{OmpA} \Delta \mathrm{OmpA}$ were assessed. Given that the complementary ompA gene in KJL2::OmpA $\triangle \mathrm{OmpA}$ was driven by the L2 promoter, a preliminary test was performed to determine the $\beta$-lactam concentration at which ompA can be expressed in the KJL2::OmpA $\triangle \mathrm{OmpA}$. The swimming motility of KJL2::OmpA $\triangle \mathrm{OmpA}$ was tested with and without cefuroxime at different concentrations. Unexpectedly, KJL2::OmpA $\triangle \mathrm{OmpA}$ displayed comparable swimming motility in cefuroxime-free and cefuroxime-containing plates (Figure 2A), indicating that the ompA of KJL2::OmpA $\triangle \mathrm{OmpA}$ expressed by $P_{L 2}$, without $\beta$-lactam challenge, is sufficient to compensate for the functional defect caused by the ompA deletion. The mechanism underlying this phenotype will be explained later. Thus, the following functional experiments were carried out under $\beta$-lactam-free conditions. Compared to the $30 \pm 3.2 \mathrm{~mm}$ swimming zone in wild-type $\mathrm{KJ}$, a $13.6 \pm 1.8 \mathrm{~mm}$ swimming zone was observed in $\mathrm{KJ} \Delta \mathrm{OmpA}$ (Figure 2A). The complementary strain KJL2::OmpA $\Delta \mathrm{OmpA}$ almost reverted the swimming motility to a wild-type level (Figure 2A).

The flagellar structures of wild-type $\mathrm{KJ}, \mathrm{KJ} \Delta \mathrm{OmpA}$, and $\mathrm{KJ} 22:: \mathrm{OmpA} \Delta \mathrm{OmpA}$ were observed using transmission electron microscopy (TEM). Wild-type KJ displayed a tuft of 2-3 polar flagella (Figure 2B), which is consistent with previous reports [45]. In contrast, $\mathrm{KJ} \Delta \mathrm{OmpA}$ cells had short flagella that were sometimes located at a subpolar position. The complementary strain KJL2::OmpA $\Delta \mathrm{OmpA}$ restored the wild-type flagellar structure (Figure 2B). Next, flagellin protein levels were evaluated using a Western blotting assay. Considering the necessity of the FliC negative control for Western blotting, we aimed to construct a FliC-null mutant. In a genome-wide search, we noticed three flagellin-like genes in the S. maltophilia K279a genome, Smlt2306, Smlt2305, and Smlt2304. We annotated these three genes as $f l i C 1, f l i C 2$, and $f l i C 3$, respectively (Figure $3 \mathrm{~A}$ ). As the role of these three genes in flagellum formation is not yet understood, the flagellin-null mutant was constructed by simultaneously deleting the three genes to yield the mutant $\mathrm{KJ} \triangle \mathrm{FliC} 1 \mathrm{C} 2 \mathrm{C} 3$. The Western blotting results demonstrated that $\mathrm{KJ}, \mathrm{KJ} \Delta \mathrm{OmpA}$, and KJL2::OmpA $\Delta \mathrm{OmpA}$ had comparable cytoplasmic flagellin protein levels (Figure 2C). 
(A)

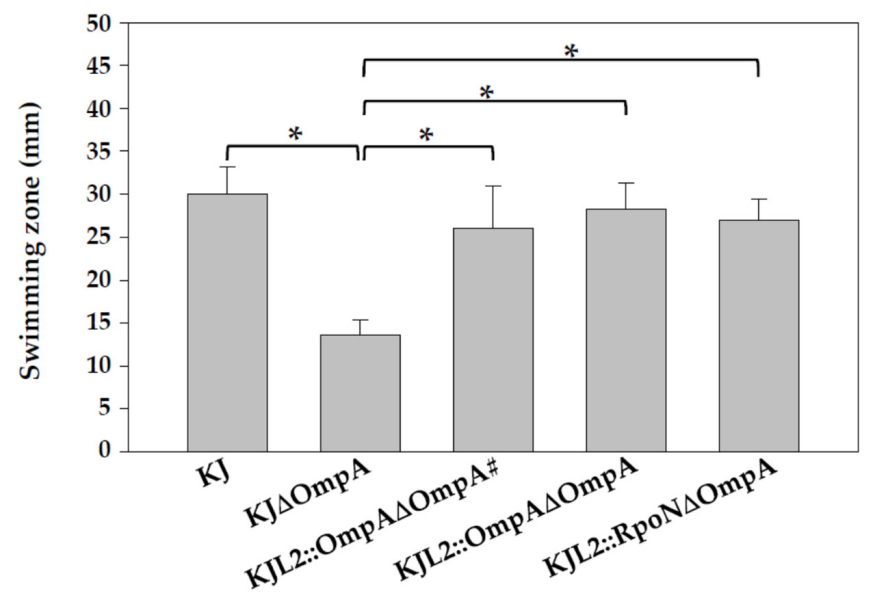

(B)

KJ

$\mathrm{KJ} \Delta \mathrm{OmpA}$

KJL2::OmpA $\Delta \mathrm{OmpA}$

KJL2::RpoN $\Delta \mathrm{OmpA}$

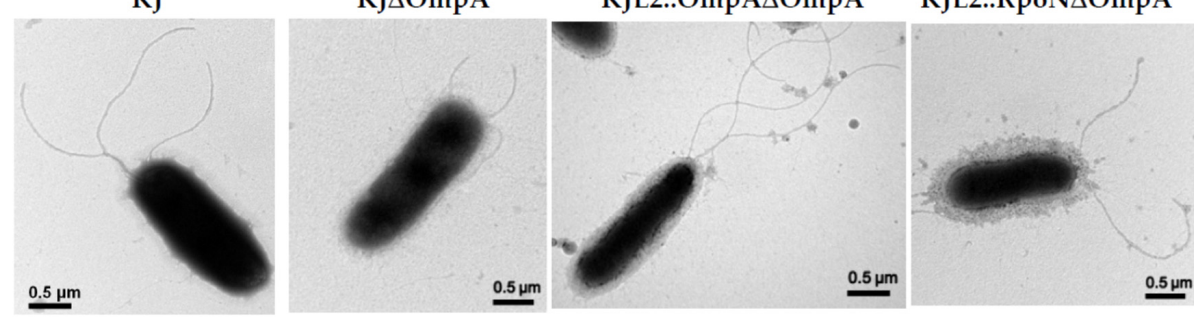

\begin{tabular}{|l|c|c|}
\hline \multicolumn{1}{|c|}{ Strain } & No. of flagellum/cell & Flagellum length $(\mu \mathrm{m})$ \\
\hline KJ & $2.67 \pm 0.47$ & $2.80 \pm 0.80$ \\
\hline KJ $\Delta \mathrm{OmpA}$ & $2.01 \pm 1.40$ & $0.96 \pm 0.35$ \\
\hline KJL2::OmpA $\Delta \mathrm{OmpA}$ & $3 \pm 0$ & $3.01 \pm 0.34$ \\
\hline KJL2::RpoN $\Delta \mathrm{OmpA}$ & $2 \pm 0$ & $3.45 \pm 0.86$ \\
\hline
\end{tabular}

(C)

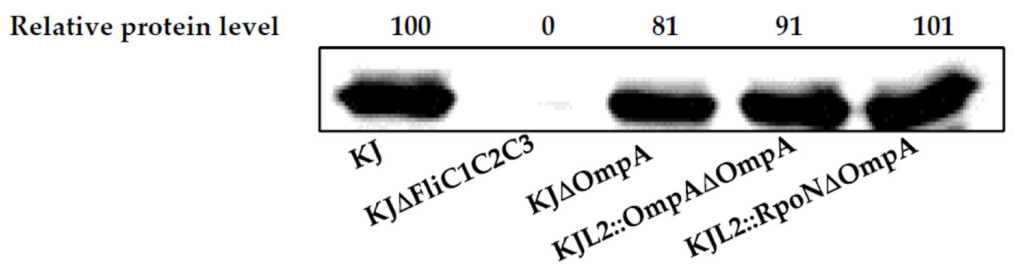

Figure 2. The swimming motility, flagellum morphology, and intracellular flagellin proteins levels of wild-type KJ, its derived ompA mutant, and complementary strains. Overnighted cultured bacterial cells were inoculated into fresh LB broth and then grown for $5 \mathrm{~h}$ before testing. (A) Swimming motility. Five $\mu \mathrm{L}$ of bacterial cell suspension were inoculated into swimming agar and then incubated at $37^{\circ} \mathrm{C}$ for $48 \mathrm{~h}$. The swimming zones were recorded. \#, Cefuroxime of $50 \mu \mathrm{g} / \mathrm{mL}$ was added into the swimming agar. The data are the means of three independent experiments. The error bars indicate the standard deviations of three triplicate samples. ${ }^{*}, p<0.05$, significance calculated using the Student's $t$-test. (B) Flagella morphology. The flagella were negatively stained with $1 \%$ phosphotungstic acid ( $\mathrm{pH} 7.4$ ) and observed using TEM. The average flagellum numbers per cell and flagellum length were calculated from at least four cells. (C) Western blotting of flagellin protein levels in a whole-cell extract. The proteins of a whole-cell extract were separated using SDS-PAGE and immunoblotting with anti-FliC3 and anti-RpoA antibodies. The RpoA protein served as an intracellular control. The relative protein level of the FliC protein was normalized to the RpoA protein. 


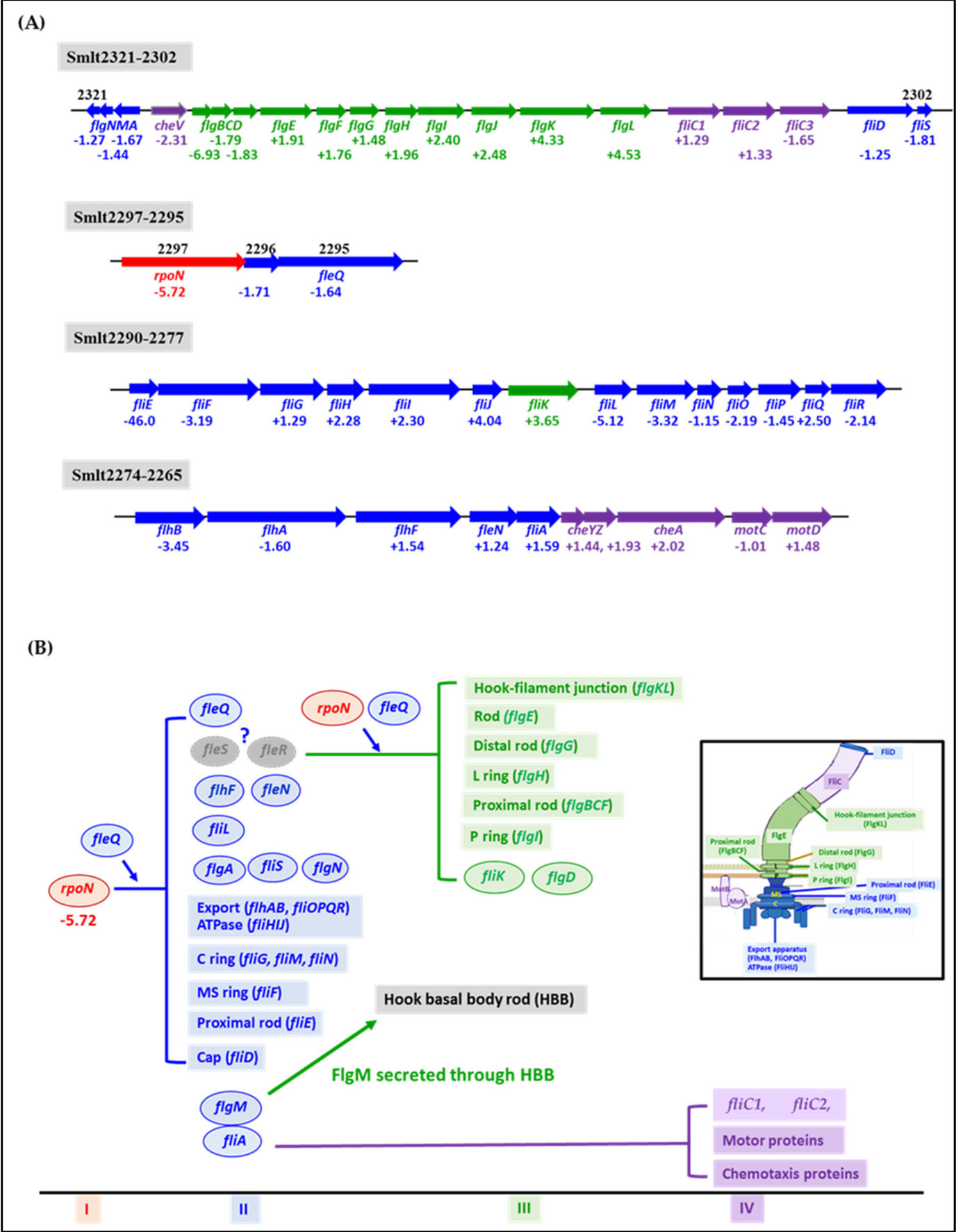

Figure 3. Flagellum synthesis model and RNA-seq transcriptome analysis of wild-type KJ and the ompA mutant, KJ $\Delta \mathrm{OmpA}$. (A) Genomic organization of the genes involved in flagellum synthesis and action. The flagellum-associated genes were located in four clusters. The genes classified in class I, II, III, and IV are marked in red, blue, green, and purple, respectively. The numbers below the genes indicate the gene expression changes analyzed using a transcriptome assay. Positive values represent an upregulation in $\mathrm{KJ} \Delta \mathrm{OmpA}$, whereas negative values indicate a downregulation in $\mathrm{KJ} \Delta \mathrm{OmpA}$. (B) A schematic model showing the transcriptional hierarchy of the genes involved in flagellum synthesis in S. maltophilia. The flagellum synthesis model of S. maltophilia is proposed by referencing the known P. aeruginosa flagellum model, as most of the flagellum synthesis-associated genes of P. aeruginosa are highly conserved in the S. maltophilia genome. The genes classified in class I, II, III, and IV are marked in red, blue, green, and purple, respectively. The genes symbolized by rectangles represent the encoded proteins composing the flagellum and the ovals represent regulatory proteins. 


\subsection{Establishment of a Putative Flagellum Synthesis Model for S. maltophilia}

Information concerning flagellum synthesis and action in S. maltophilia is relatively scarce, and the hierarchical expression circuit has not been established. Although flagellum synthesis is well-studied in E. coli and P. aeruginosa, these systems are obviously different $[27,28]$. We surveyed the S. maltophilia K279a genome [40] for flagellum-associated genes and found that the flagellum system of $S$. maltophilia was more similar to that of $P$. aeruginosa [27]. To study the linkage between swimming compromise and ompA deletion, we thoroughly analyzed the S. maltophilia K279a genome to identify genes with known or predicted function of flagellum biogenesis or function, based on the known P. aeruginosa flagellum model. Genes known or predicted to be involved in chemotaxis and energy control were also included because of their genetic linkage to these flagellar genes. We identified 46 genes encoding the structural, assembly, or regulatory proteins of the flagellum in the sequenced K279a genome (Table S2). Most of these genes have sufficient homology with their orthologs in P. aeruginosa (Table S2). These genes are located in four clusters of chromosomes (Figure 3A). Most of the known flagellum-associated genes of P. aeruginosa are highly conserved in S. maltophilia, except for fleRS, fleP, and fleL.

A putative flagellum model of $S$. maltophilia was preliminarily proposed based on the P. aeruginosa model (Figure S2). FleQ and FliA are master regulators located in class I. FleQ works in concert with RpoN to activate the expression of class II genes. FlgM, a member of class II, interacts with FliA, resulting in FliA sequestration. In the P. aeruginosa model, class III genes are activated by class II-encoded FleRS in an RpoN-dependent manner [46]. However, no fleRS homologs have been identified in the S. maltophilia K279a genome. The regulatory components responsible for the expression of class III genes are relatively unclear. Upon completion of the hook basal body (HBB) by class II- and class III-encoded proteins, FlgM is secreted by the HBB and the liberated FliA activates the transcription of class IV genes.

To confirm the reliability of the preliminarily proposed flagellum model (Figure S2), we constructed isogenic deletion mutants of fleQ (Smlt2295), rpoN (Smlt2297), and fliA (Smlt2270), whose encoded proteins are predicted to function as regulators at the first hierarchical level of the P. aeruginosa flagellum model. None of the constructed mutants exhibited observable changes in their colony shapes and growth patterns. Wild-type KJ, $\mathrm{KJ} \Delta$ FleQ, $\mathrm{KJ} \Delta \mathrm{RpoN}$, and $\mathrm{KJ} \Delta$ FliA were subjected to qRT-PCR analysis to confirm the accuracy of the hierarchical model. We randomly selected the following genes as representatives of the four classes of the proposed model (Figure S2) for qRT-PCR testing: fleQ, rpoN, and fliA for class I; fliD and fliN for class II; flgG and flgK for class III; and fliCl, cheV, and $m o t C$ for class IV. The inactivation of $r p o N$ reduced the expression of all the genes assayed, supporting RpoN as a class I regulator. FleQ deletion resulted in the downregulation of all the genes assayed except rpoN. Interestingly, rpoN was significantly upregulated in the fle $Q$ mutant. The loss-of-function of fliA downregulated $f l i C, c h e V$, and $m o t C$, but upregulated $f l i N$, flg $G$, and $f l g K$ (Figure $4 \mathrm{~A}$ ). The swimming motility, flagellum morphology, and flagellin protein levels of $\mathrm{KJ} \Delta \mathrm{FleQ}, \mathrm{KJ} \Delta \mathrm{RpoN}$, and $\mathrm{KJ} \Delta \mathrm{FliA}$ were also assessed. All of the mutants tested completely lost swimming motility (Figure 4B) and had no flagella (Figure 4C). This was further confirmed by the presence of few intracellular flagellin proteins (Figure 4D). Furthermore, the qRT-PCR results were validated using $x y l E$ reporter constructs in the $r p o N$, fleQ, and fliA mutant backgrounds. Using the plasmid pRpoN $\mathrm{xylE}_{\mathrm{x}}\left(\mathrm{C}_{r p o N^{-}} x y l E\right.$ transcriptional fusion), we measured $r p o N$ promoter activity in the wild-type $\mathrm{KJ}$, fliA, rpoN, and fleQ mutants. Compared to $\mathrm{KJ}\left(\mathrm{pRpoN}_{\mathrm{xylE}}\right), \mathrm{KJ} \Delta \mathrm{FleQ}\left(\mathrm{pRpoN}_{\mathrm{xylE}}\right)$ had an increased $\mathrm{C} 23 \mathrm{O}$ activity and $\mathrm{KJ} \Delta \mathrm{FliA}\left(\mathrm{pRpoN}_{\mathrm{xylE}}\right.$ ) displayed a comparable one (Figure S3), consistent with the qRT-PCR results (Figure $4 \mathrm{~A}$ ). We also observed that no $\mathrm{C} 23 \mathrm{O}$ activity was detected in $\mathrm{KJ} \Delta \mathrm{RpoN}\left(\mathrm{pRpoN}_{\mathrm{xylE}}\right)$, indicating that RpoN has a positive autoregulation circuit. 


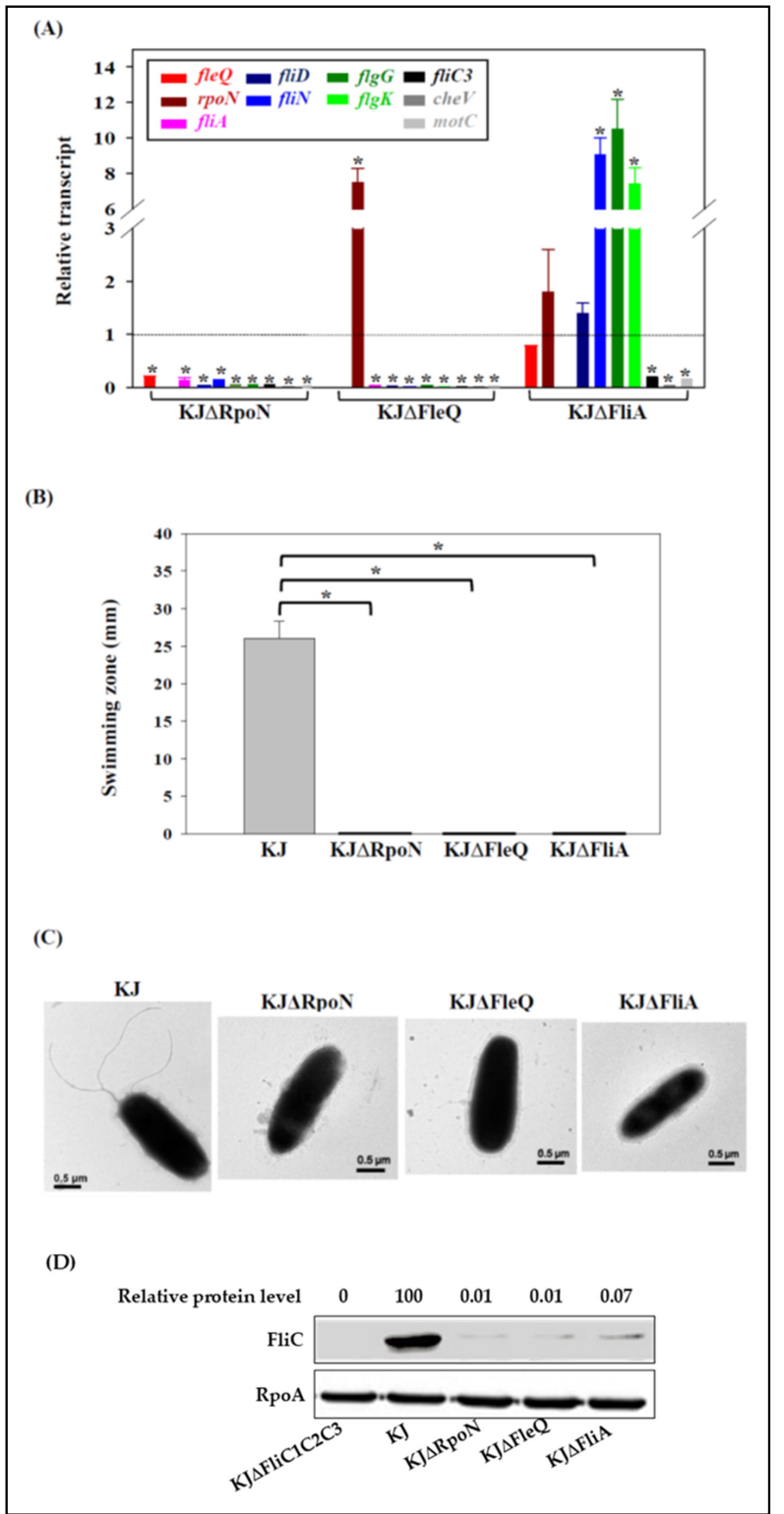

Figure 4. Impact of $r p o N$, fleQ, and fliA on flagellum-associated gene expression, swimming motility, flagellum morphology, and flagellin protein levels. (A) The impact of $r p o N$, fleQ, and fliA on flagellumassociated gene expression. Overnighted cultured bacterial cells $(\mathrm{KJ}, \mathrm{KJ} \Delta \mathrm{RpoN}, \mathrm{KJ} \Delta \mathrm{FleQ}$, and $\mathrm{KJ} \Delta \mathrm{FliA}$ ) were inoculated into fresh $\mathrm{LB}$ broth and then grown for $5 \mathrm{~h}$ before a qRT-PCR. The expression levels of the assayed genes were normalized to those of the $16 \mathrm{~S}$ ribosomal RNA gene. The relative transcript was calculated by dividing the mRNA levels of the wild-type by those of the mutant indicated. The mean and SD of the three independent experiments are shown. ${ }^{*}$, a relative transcript greater than 2 or less than 0.5 was considered to be significant. (B) The impact of rpoN, fleQ, and fliA on swimming motility. Overnighted cultured bacterial cells were inoculated into fresh LB broth and then grown for $5 \mathrm{~h}$ before testing. A five-microliter bacterial cell suspension was inoculated into swimming agar and then incubated at $37^{\circ} \mathrm{C}$ for $48 \mathrm{~h}$. The swimming zones were recorded. The data are the means of three independent experiments. The error bars indicate the standard deviations of three triplicate samples. ${ }^{*}, p<0.05$, significance calculated using the Student's $t$-test. (C) The impact of $r p o N$, fleQ, and fliA on flagella morphology. The flagella were negatively stained with $1 \%$ phosphotungstic acid (pH 7.4) and observed using TEM. (D) The impact of rpoN, fleQ, and fliA on flagellin protein levels. The proteins of a whole-cell extract were separated using SDS-PAGE and immunoblotting with anti-FliC3 and anti-RpoA antibodies. 
The flagellum hierarchy expression model of $S$. maltophilia was thus amended as follows (Figure 3B). RpoN is at the top of the regulatory hierarchy and drives the transcription of class II genes (labeled as a red oval in Figure 3B). Notably, the expression of fliA and fleQ was almost abolished in the rpoN mutant, indicating that fle $Q$ and fliA are members of the RpoN regulon. Thus, fleQ and fliA were arranged at the class II level in the S. maltophilia model. This feature differs from the known model of P. aeruginosa. The proteins encoded by the class II genes included the flagellum component proteins (labeled as blue rectangles in Figure 3B) and regulatory proteins (labeled as blue ovals in Figure 3B). The key regulators for the expression of class III genes, such as FleSR of $P$. aeruginosa, are not immediately clear, but the qRT-PCR results supported the suggestion that RpoN and FleQ are involved in the expression of some class III genes. The proteins encoded by class III genes included flagellum component proteins, FlgBCDGHIKL (labeled as green rectangles in Figure $3 \mathrm{~B}$ ) and regulatory proteins (FliK and FlgD) involved in flagellum hook length and modification (labeled as green ovals in Figure 3B). After FlgM is secreted via HBB, free FliA switches the expression of class IV genes. The proteins encoded by class IV genes included flagellins, flagellum motor proteins, and chemotaxis proteins (labeled as purple rectangles in Figure 3B). In the following study, we applied the model proposed in Figure $3 \mathrm{~B}$ as the rationale for the experimental design.

\subsection{RpoN Downregulation Is Responsible for $\Delta$ ompA-Mediated Swimming Compromise}

To identify the target genes responsible for swimming compromise in the ompA mutant, an RNA-Seq transcriptome assay of wild-type $\mathrm{KJ}$ and $\mathrm{KJ} \Delta \mathrm{OmpA}$ was conducted. A statistical significance was defined as an absolute fold change in RPKM equal to or greater than three. The transcriptome analysis revealed that 144 and 190 out of a total of 4695 genes were significantly increased and decreased, respectively, in $\mathrm{KJ} \Delta \mathrm{OmpA}$ compared to wildtype KJ (Table S3). We noticed that the L2 (Smlt3722) gene of KJ $\Delta \mathrm{OmpA}$ showed a five-fold increase in the transcriptome assay (Table S3), indicating that the L2 gene is partially derepressed in $\mathrm{KJ} \Delta \mathrm{OmpA}$. This observation provided a reasonable explanation for why the complementary strain KJL2::OmpA $\Delta$ OmpA could revert to swimming motility without a $\beta$-lactam addition (Figure 2A). To validate the transcriptome results, qRT-PCR analysis was performed on the six selected genes. Relative to wild-type KJ, the expression of the six genes was corroborated by the transcriptome results in $\mathrm{KJ} \Delta \mathrm{OmpA}$ and mostly reverted to wild-type levels in KJL2::OmpA $\Delta$ OmpA (Figure 5).

As the first step in identifying the possible candidate genes responsible for the $\triangle o m p A$-mediated swimming compromise, we thoroughly analyzed the transcriptome data (Table S3), based on our proposed hierarchical regulation model for flagellum synthesis in S. maltophilia (Figure 3B). The surveyed genes included flagellum biosynthesis, flagellum regulation, flagellum motor, and chemotaxis (Table 1). Among the 46 genes surveyed, seven and four genes were significantly downregulated and upregulated in $\mathrm{KJ} \Delta \mathrm{OmpA}$, respectively (Table 1, Figure $3 \mathrm{~A}$ ). The proteins encoded by the downregulated genes participated in global regulation (RpoN), flagellar assembly (FlhB, FliE, FliF, FliM, and $\mathrm{FlgB}$ ), and motor switch control (FliL). The upregulated genes were $f l i J, f l i K, f l g K$, and $f l g L$, whose encoded proteins are implicated in hook length control and hook assembly. According to the proposed hierarchy model in Figure 3B, RpoN is the key candidate responsible for $\triangle o m p A$-mediated swimming compromise because it is located in the first class of the four-class model. 


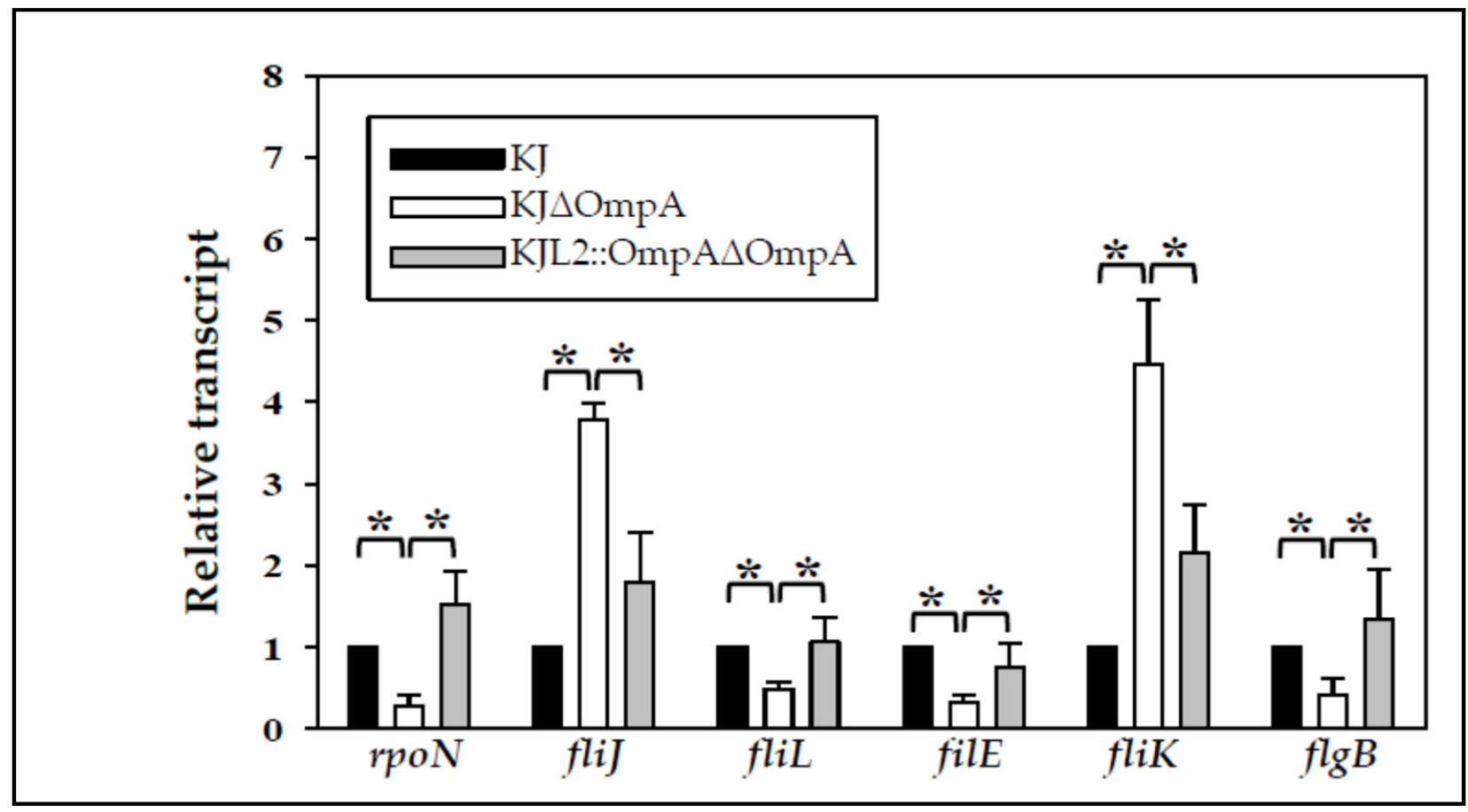

Figure 5. Impact of $о т р A$ on the expression of flagellum-associated genes. Overnighted cultured bacterial cells (KJ, $\mathrm{KJ} \Delta \mathrm{OmpA}$, and KJL2:OmpA $\triangle \mathrm{OmpA}$ ) were inoculated into fresh LB broth and then grown for $5 \mathrm{~h}$ before a qRT-PCR. The expression levels of the assayed genes were normalized to those of the $16 \mathrm{~S}$ ribosomal RNA gene. The relative transcript was calculated using the wild-type KJ level as one. The mean and SD of the three independent experiments are shown. ${ }^{*}, p<0.05$, significance calculated using the Student's $t$-test.

Table 1. Swimming-associated genes differently expressed in S. maltophilia KJ and KJ $\Delta \mathrm{OmpA}$.

\begin{tabular}{|c|c|c|c|c|c|}
\hline \multirow{2}{*}{ Smlt } & \multirow{2}{*}{ Gene } & \multicolumn{2}{|c|}{ RPKM $^{a}$} & \multirow{2}{*}{ Fold } & \multirow{2}{*}{ Encoded Protein } \\
\hline & & KJ & $\mathrm{KJ} \Delta \mathrm{OmpA}$ & & \\
\hline \multicolumn{6}{|c|}{ Class I } \\
\hline 2297 & rpoN & 104.48 & 18.26 & -5.72 & $\sigma 54$ sigma factor \\
\hline \multicolumn{6}{|c|}{ Class II } \\
\hline 2295 & fleQ & 226.20 & 137.15 & -1.64 & transcriptional activator \\
\hline 2270 & fliA & 98.17 & 156.68 & +1.59 & $\sigma 28$ sigma factor \\
\hline 2271 & fleN & 159.21 & 197.77 & +1.24 & flagella number regulator \\
\hline 2272 & flhF & 14.26 & 22.09 & +1.54 & flagellar polar location \\
\hline 2273 & $\operatorname{flh} A$ & 8.14 & 5.07 & -1.60 & flagellar export protein \\
\hline 2274 & $f l h B$ & 8.63 & 2.49 & -3.45 & flagellar export protein \\
\hline 2277 & fliR & 14.57 & 6.78 & -2.14 & flagellar export protein \\
\hline 2278 & fliQ & 19.71 & 49.47 & 2.50 & flagellar export protein \\
\hline 2279 & fliP & 15.18 & 10.43 & -1.45 & flagellar export protein \\
\hline 2280 & fliO & 38.14 & 17.37 & -2.19 & flagellar export protein \\
\hline 2281 & fliN & 52.03 & 45.24 & -1.15 & flagellar motor switch protein \\
\hline
\end{tabular}


Table 1. Cont.

\begin{tabular}{|c|c|c|c|c|c|}
\hline \multirow{2}{*}{ Smlt } & \multirow{2}{*}{ Gene } & \multicolumn{2}{|c|}{ RPKM $^{a}$} & \multirow{2}{*}{ Fold } & \multirow{2}{*}{ Encoded Protein } \\
\hline & & KJ & $\mathrm{KJ} \Delta \mathrm{OmpA}$ & & \\
\hline 2282 & fliM & 16.48 & 4.96 & -3.32 & flagellar motor switch protein \\
\hline 2283 & fliL & 19.49 & 3.80 & -5.12 & basal body-associated protein \\
\hline 2285 & fliJ & 12.00 & 48.53 & +4.04 & chaperone, export of hook proteins \\
\hline 2286 & fliI & 26.64 & 61.27 & +2.30 & flagellum-specific ATPase \\
\hline 2287 & $f l i H$ & 42.91 & 98.07 & +2.28 & flagella assembly protein \\
\hline 2288 & fliG & 56.09 & 72.82 & +1.29 & motor switch protein \\
\hline 2289 & fliF & 47.05 & 14.73 & -3.19 & basal body MS ring \\
\hline 2290 & fliE & 45.59 & 1.00 & -45.6 & basal body MS ring/rod adapter \\
\hline 2302 & flis & 664.26 & 365.25 & -1.81 & chaperone for filament elongation \\
\hline 2303 & fliD & 297.89 & 237.50 & -1.25 & filament cap \\
\hline 2319 & $f \lg A$ & 46.60 & 27.82 & -1.67 & $\begin{array}{l}\text { basal body P-ring biosynthesis } \\
\text { protein }\end{array}$ \\
\hline 2320 & $f \lg M$ & 1908.60 & 1317.64 & -1.44 & anti-sigma factor FlgM \\
\hline 2321 & $f \lg N$ & 775.79 & 607.01 & -1.27 & chaperone \\
\hline \multicolumn{6}{|c|}{ Class III } \\
\hline 2284 & $f l i K$ & 19.85 & 72.54 & +3.65 & flagellar hook-length control \\
\hline 2307 & $f l g L$ & 54.28 & 246.26 & +4.53 & hook-filament junctional protein \\
\hline 2308 & $f l g K$ & 49.76 & 215.68 & +4.33 & hook-filament junctional protein \\
\hline 2309 & $f l g J$ & 20.28 & 50.41 & +2.48 & flagellum specific muramidase \\
\hline 2310 & flgI & 15.17 & 36.478 & +2.40 & basal body P-ring \\
\hline 2311 & $f \lg H$ & 36.78 & 72.24 & +1.96 & basal body L-ring \\
\hline 2312 & $f \lg G$ & 60.97 & 90.60 & +1.48 & basal body rod \\
\hline 2313 & $\operatorname{flg} F$ & 5.34 & 9.46 & +1.76 & basal body rod \\
\hline 2314 & $f l g E$ & 13.12 & 25.11 & +1.91 & hook \\
\hline 2315 & $f l g D$ & 24.64 & 13.39 & -1.83 & hook capping protein \\
\hline 2316 & $f \lg C$ & 15.23 & 8.49 & -1.79 & basal body rod \\
\hline 2317 & $f \lg B$ & 48.91 & 7.05 & -6.93 & basal body rod \\
\hline \multicolumn{6}{|c|}{ Class IV } \\
\hline 2265 & motD & 71.76 & 106.27 & +1.48 & flagellar motor protein \\
\hline 2266 & $\operatorname{mot} C$ & 353.41 & 347.85 & -1.01 & flagellar motor protein \\
\hline 2267 & cheA & 92.22 & 186.55 & +2.02 & chemotaxis sensor kinase regulator \\
\hline 2268 & cheZ & 241.78 & 467.49 & +1.93 & chemotaxis protein \\
\hline 2269 & cheY & 268.99 & 388.99 & +1.44 & chemotaxis response regulator \\
\hline 2304 & fliC1 & 395.14 & 510.14 & +1.29 & flagellin \\
\hline 2305 & fliC2 & 23.32 & 31.10 & +1.33 & flagellin \\
\hline 2306 & fliC3 & 180.47 & 109.26 & -1.65 & flagellin \\
\hline 2318 & cheV & 164.29 & 70.89 & -2.31 & chemotaxis response regulator \\
\hline
\end{tabular}

${ }^{a}$ RPKM, Reads Per Kilobase of transcript per Million reads mapped. Bold: Statistical significance was defined as an absolute fold change in RPKM equal to or greater than 3. 
To test this notion, $\mathrm{KJ} \Delta \mathrm{OmpA}$ was complemented with an intact $r p o N$ gene. The $L 2$ gene was replaced with the rpoN gene using double cross-over recombination to yield KJL2::RpoN, and ompA was in-frame deleted from the chromosome of KJL2::RpoN, generating KJL2::RpoN $\triangle$ OmpA (Figure 1). KJL2::RpoN displayed swimming motility comparable to that of wild-type KJ. However, compared to KJ $\Delta \mathrm{OmpA}$, KJL2::RpoN $\Delta \mathrm{OmpA}$ showed swimming motility restoration to the wild-type level (Figure 2A). The TEM analysis revealed that KJL2::RpoN $\Delta$ OmpA displayed a wild-type flagellar structure (Figure $2 \mathrm{~B}$ ). The intracellular FliC protein level of KJL2::RpoN $\Delta \mathrm{OmpA}$ was also comparable to that of wild-type KJ (Figure 2C).

\section{Discussion}

For a pathogen, the first step in pathogenesis is to establish an initial attachment to the host cells and facilitate colonization. Colonization requires a functional flagellum; therefore, swimming motility is a crucial virulence factor for pathogens [47]. Although the flagellum and swimming motility are well characterized in several Gram-negative bacteria, such as E. coli, V. cholerae, and P. aeruginosa, little is known regarding these aspects in S. maltophilia. In this study, we first proposed the hierarchical organization of flagella synthesis genes in S. maltophilia. Many of the approximately 59 genes involved in flagella biosynthesis in $P$. aeruginosa are conserved in the $S$. maltophilia genome. However, some P. aeruginosa flagellar genes have not been identified in S. maltophilia (such as FleRS, FleP, and FleL), and some flagellar genes appear to be unique to S. maltophilia (such as Smlt2296). Furthermore, $P$. aeruginosa harbors a flagellin gene ( $f l i C$ ), either type-a or type-b [48]; nevertheless, there are three flagellin genes $(\mathrm{fliC} 1$, fliC2, and fliC3) in the genome of S. maltophilia K279a.

In addition to the differences in gene organization, some regulatory mechanisms were noted to be different in the hierarchical models of S. maltophilia and P. aeruginosa, as follows: (i) Class I genes, fleQ and fliA, are constitutively expressed in P. aeruginosa. FleQ is considered the master regulator of the flagellar regulon [27] and works in concert with RpoN to trigger the expression of class II genes [49]. Furthermore, FliA is a critical regulator of class IV genes expression [49]. The transcription of fleQ and fliA is independent of RpoN in P. aeruginosa [50,51]. Nevertheless, in S. maltophilia, rpoN inactivation almost abolished the transcription of fleQ, fliA, and the genes of class II, class III, and class IV (Figure 3A), supporting the suggestion that $r p o N$, rather than fleQ and fliA, is at the top of the flagellar regulatory cascade in S. maltophilia. Thus, RpoN in S. maltophilia appears to have a more global regulatory spectrum than that in P. aeruginosa. Furthermore, RpoN has the feature of positive autoregulation (Figure S3). Therefore, the RpoN regulon of S. maltophilia encompasses the class I, II, III, and IV genes. (ii) The regulation of RpoN on fleQ did not appear to be a simple one-way regulatory circuit in S. maltophilia. The rpoN transcript was apparently upregulated in the fle $Q$ mutant and was almost unexpressed in the rpoN mutant (Figure 3A and Figure S3). This phenomenon was not observed in P. aeruginosa. (iii) Similar to P. aeruginosa FliA, S. maltophilia FliA is the key regulator for the expression of class IV genes. Nevertheless, we observed that FliA of S. maltophilia can negatively regulate some class II and class III genes, thus extending our understanding of FliA. Interestingly, RpoN positively controls the expression of fliA and FliA negatively regulates the expression of fli $N$, flg $G$, and $f l g K$; however, the expression of $f l i N$, flg $G$, and $f l g K$ was almost abolished in $\mathrm{KJ} \Delta \mathrm{RpoN}$ (Figure 3A), suggesting the presence of unidentified regulator(s) participating in the complex regulatory circuit.

OMPs can provide the structural integrity of bacteria, which is critical for flagellar assembly and swimming ability. The linkage between $\beta$-barrel OMPs and swimming motility has been reported in some bacteria, but the impact of OMP deletion on swimming motility is varied. The deletion of $\operatorname{ompX}$ increases swimming motility in extraintestinal pathogenic E. coli [52]. However, in $V$. cholerae, flgO and flgP deletion mutants show decreased swimming motility, and the stability of flagella is significantly affected [53]. In addition, Bari et al. have also reported that ompU and ompT deletion mutants of $V$. cholerae showed thinner flagella, significant defects in swimming motility, and increased shedding 
of flagella sheath proteins in the culture supernatant [54]. A similar observation was also reported for the lamB deletion mutant of Aeromonas veronii; its lamB deletion mutant almost lost swimming motility, and shedding flagella were found in the visual field of the TEM examination [55]. In this study, we demonstrated that the omp $A$ deletion mutant of S. maltophilia has shorter flagella and defective swimming motility. Furthermore, we also revealed that $\triangle o m p A$-mediated $r p o N$ downregulation is a critical factor responsible for swimming compromise in $\mathrm{KJ} \Delta \mathrm{OmpA}$. Precisely how omp $A$ deletion downregulates $r p o N$ expression remains unclear. The Gram-negative envelope protects the bacteria from the environment. The loss of abundant OmpA in the OM can cause envelope damage, which may trigger the envelope stress responses to maintain envelope homeostasis. The envelope stress responses extensively and diversely exist in different microorganisms, including $\sigma^{\mathrm{E}}$ response, Cpx response, Rcs response, Bae response, and Psp response [56]. We presume that the envelope stress response could be the connection between omp $A$ deletion and rpoN downregulation. This issue needs to be further explored.

The contribution of OmpA to bacterial conjugation has been reported in E. coli [57], and the underlying mechanism is that the TraN protein encoded by the F plasmid interacts with OmpA in recipient cells, thus increasing their mating efficiency [58]. In this study, we verified that S. maltophilia OmpA, similar to E. coli OmpA, is a critical protein in recipient cells for successful conjugation. Conjugation is instrumental to the horizontal transfer of antibiotic resistance genes in clinical environments and enhances the spread of antibiotic resistance among bacteria [59]. Thus, blocking conjugation can be regarded as a tool against antibiotic resistance [60].

S. maltophilia is ubiquitous in the environment and is an increasingly opportunistic pathogen. The attribute of multidrug resistance increases the difficulty of treating S. maltophilia infection [61]. Thus, it is important to develop new treatment strategies to combat S. maltophilia infections. Swimming is a critical virulence factor involved in bacterial pathogenesis. Conjugation is an efficient method for horizontal transfer of antibiotic resistance. In this study, we demonstrated that the OmpA of S. maltophilia significantly contributes to swimming and conjugation; thus, blocking the OmpA function may attenuate the bacterial pathogenicity and occurrence of antibiotic resistance. Therefore, OmpA is an ideal target for inhibitor design. For Gram-negative bacteria, the double membranes may be a natural barrier for the entrance of foreign molecules [2,3]. Given that OmpA is the OMP of the greatest abundance in S. maltophilia, the accessibility of an OmpA inhibitor to OmpA can be highly efficient. Therefore, the development of an OmpA inhibitor is a feasible strategy to combat S. maltophilia infection.

Supplementary Materials: The following are available online at https:/ /www.mdpi.com/article/ 10.3390/microorganisms9061216/s1, Figure S1: The SDS-PAGE of OMPs from wild-type KJ, $\mathrm{KJ} \Delta \mathrm{OmpA}$, and KJL2::OmpA $\triangle \mathrm{OmpA}$, Figure S2: The preliminary flagellum synthesis model of S. maltophilia based on the known P. aeruginosa model, Figure S3: The C23O activities of $\mathrm{KJ}\left(\mathrm{pRpoN}_{\mathrm{xylE}}\right)$, $\mathrm{KJ} \Delta \mathrm{FleQ}\left(\mathrm{pRpoN} \mathrm{xylE}_{\mathrm{E}}\right), \mathrm{KJ} \Delta \mathrm{FliA}\left(\mathrm{pRpoN}_{\mathrm{xylE}}\right)$, and $\mathrm{KJ} \Delta \mathrm{RpoN}\left(\mathrm{pRpoN}_{\mathrm{xylE}}\right)$, Table S1: The bacterial strains, plasmids, and primers used in this study, Table S2: Comparison of the flagella synthesisassociated proteins between S. maltophilia and P. aeruginosa, Table S3: Transcriptomic analysis of S. maltophilia wild-type $\mathrm{KJ}$ and omp $A$ mutant $\mathrm{KJ} \triangle \mathrm{OmpA}$.

Author Contributions: Conceptualization, C.-H.L. and T.-C.Y.; methodology, C.-L.C., H.-H.H., and L.-H.L.; software, Y.-T.L.; validation, C.-H.L. and T.-C.Y.; formal analysis, C.-L.C., H.-H.H., and L.-H.L.; resources, Y.-T.L.; writing—original draft preparation, C.-H.L. and H.-H.H.; writing—review and editing, T.-C.Y.; supervision, C.-H.L. and T.-C.Y.; project administration, C.-H.L. and T.-C.Y.; funding acquisition, C.-H.L. and T.-C.Y. All authors have read and agreed to the published version of the manuscript.

Funding: This research was funded by the Ministry of Science and Technology of Taiwan, MOST 108-2320-B-010-032-MY3 and the NYMU-FEMH Joint Research Program, 110DN34. 
Institutional Review Board Statement: Not applicable.

Informed Consent Statement: Not applicable.

Data Availability Statement: Not applicable.

Conflicts of Interest: The authors declare no conflict of interest.

\section{References}

1. Gan, L.; Chen, S.; Jensen, G.J. Molecular organization of Gram-negative peptidoglycan. Proc. Natl. Acad. Sci. USA 2008, 105, 18953-18957. [CrossRef] [PubMed]

2. Ferrand, A.; Vergalli, J.; Pages, J.-M.; Davin-Regli, A. An intertwined network of regulation controls membrane permeability including drug influx and efflux in Enterobacteriaceae. Microorganisms 2020, 8, 833. [CrossRef] [PubMed]

3. Gajdacs, M. The concept of an ideal antibiotics: Implications for drug design. Molecules 2019, 24, 892. [CrossRef]

4. Wimley, W.C. The versatile $\beta$-barrel membrane protein. Curr. Opin. Struct. Biol. 2003, 13, 404-411. [CrossRef]

5. Silhavy, T.J.; Kahne, D.; Walker, S. The bacterial cell envelope. Cold Spring Harb. Perspect. Biol. 2010, 2, a000414. [CrossRef] [PubMed]

6. Pagel, M.; Simonet, V.; Li, J.; Lallemand, M.; Lauman, B.; Delcour, A.H. Phenotypic characterization of pore mutants of the Vibrio cholerae porin OmpU. J. Bacteriol. 2007, 189, 8593-8600. [CrossRef]

7. Tsai, Y.K.; Fung, C.P.; Lin, J.C.; Chen, J.H.; Chang, F.Y.; Chen, T.L.; Siu, L.K. Klebsiella pneumoniae outer membrane porins OmpK35 and OmpK36 play roles in both antimicrobial resistance and virulence. Antimicrob. Agents Chemother. 2011, 55, 1485-1493. [CrossRef] [PubMed]

8. Vogel, H.; Jahnig, F. Models for the structure of outer-membrane proteins of Escherichia coli derived from raman spectroscopy and prediction methods. J. Mol. Biol. 1986, 190, 191-199. [CrossRef]

9. De Mot, R.; Vanderleyden, J. The C-terminal sequence conservation between OmpA-related outer membrane proteins and MotB suggests a common function in both gram positive and gram-negative bacteria, possibly in the interaction of these domains with peptidoglycan. Mol. Microbiol. 1994, 12, 333-334. [CrossRef]

10. Park, J.S.; Lee, W.C.; Yeo, K.J.; Ryu, K.S.; Kumarasiri, M.; Hesek, D.; Lee, M.; Mobashery, S.; Song, J.H.; Kim, S.I.; et al. Mechanism of anchoring of OmpA protein to the cell wall peptidoglycan of the gram-negative bacterial outer membrane. FASEB J. 2012, 26, 219-228. [CrossRef]

11. Nikaido, H. Molecular basis of bacterial outer membrane permeability revisited. Microbiol. Mol. Biol. Rev. 2003, 67, 593-656. [CrossRef] [PubMed]

12. Smith, S.G.; Mahon, V.; Lambert, M.A.; Fagan, R.P. A molecular Swiss army knife: OmpA structure, function and expression. FEMS Microbiol. Lett. 2007, 273, 1-11. [CrossRef] [PubMed]

13. Smani, Y.; Fabrega, A.; Roca, I.; Sanchez-Encinales, V.; Vila, J.; Pachon, J. Role of OmpA in the multidrug resistance phenotype of Acinetobacter baumannii. Antimicrob. Agents Chemother. 2014, 58, 1806-1808. [CrossRef] [PubMed]

14. Nie, D.; Hu, Y.; Chen, Z.; Li, M.; Hou, Z.; Luo, X.; Mao, X.; Xue, X. Outer membrane protein A (OmpA) as a potential therapeutic target for Acinetobacter baumannii infection. J. Biomed. Sci. 2020, 27, 26. [CrossRef]

15. Koebnik, R.; Locher, K.P.; Van Gelder, P. Structure and function of bacterial outer membrane proteins: Barrels in a nutshell. Mol. Microbiol. 2000, 37, 239-253. [CrossRef]

16. Kim, S.A.; Yoo, S.M.; Hyun, S.H.; Choi, C.H.; Yang, S.Y.; Kim, H.J.; Jang, B.C.; Suh, S.I.; Lee, J.C. Global gene expression patterns and induction of innate immune response in human laryngeal epithelial cells in response to Acinetobacter baumannii outer membrane protein A. FEMS Immunol. Med. Microbiol. 2008, 54, 45-52. [CrossRef] [PubMed]

17. Chalifour, A.; Jeannin, P.; Gauchat, J.F.; Blaecke, A.; Malissard, M.; N'Guyen, T.; Thieblemont, N.; Delneste, Y. Direct bacterial protein PAMP recognition by human NK cells involves TLRs and triggers alpha-defensin production. Blood 2004, 104, 1778-1783. [CrossRef]

18. Luo, G.; Lin, L.; Ibrahim, A.S.; Baquir, B.; Pantapalangkoor, P.; Bonomo, R.A.; Doi, Y.; Adams, M.D.; Russo, T.A.; Spellberg, B. Active and passive immunization protects against lethal, extreme drug resistant-Acinetobacter baumannii infection. PLoS ONE 2012, 7, e29446. [CrossRef]

19. Guan, Q.; Wang, X.; Wang, X.; Teng, D.; Mao, R.; Zhang, Y.; Wang, J. Recombinant outer membrane protein A induces a protective immune response against Escherichia coli infection in mice. Appl. Microbiol. Biotechnol. 2015, 99, 5451-5460. [CrossRef]

20. Chaban, B.; Hughes, H.V.; Beeby, M. The flagellum in bacterial pathogens: For motility and a whole lot more. Semin. Cell. Dev. Biol. 2015, 46, 91-103. [CrossRef]

21. Zhou, M.; Yang, Y.; Chen, P.; Hu, H.; Hardwidge, P.R.; Zhu, G. More than a locomotive organelle: Flagella in Escherichia coli. Appl. Microbiol. Biotechnol. 2015, 99, 8883-8890. [CrossRef]

22. Armitage, J.P.; Berry, R.M. Assembly and Dynamics of the Bacterial Flagellum. Annu. Rev. Microbiol. 2020, 74, 181-200. [CrossRef] [PubMed]

23. Apel, D.; Surette, M.G. Bringing order to a complex molecular machine: The assembly of the bacterial flagella. Biochim. Biophys. Acta 2008, 1778, 1851-1858. [CrossRef] [PubMed] 
24. Wu, J.; Newton, A. Regulation of the Caulobacter flagellar gene hierarchy; not just for motility. Mol. Microbiol. 1997, $24,233-239$. [CrossRef] [PubMed]

25. Prouty, M.G.; Correa, N.E.; Klose, K.E. The novel sigma54- and sigma28-dependent flagellar gene transcription hierarchy of Vibrio cholerae. Mol. Microbiol. 2001, 39, 1595-1609. [CrossRef] [PubMed]

26. McCarter, L.L. Polar flagellar motility of the Vibrionaceae. Microbiol. Mol. Biol. Rev. 2001, 65, 445-462. [CrossRef] [PubMed]

27. Dasgupta, N.; Wolfgang, M.C.; Goodman, A.L.; Arora, S.K.; Jyot, J.; Lory, S.; Ramphal, R. A four-tiered transcriptional regulatory circuit controls flagellar biogenesis in Pseudomonas aeruginosa. Mol. Microbiol. 2003, 50, 809-824. [CrossRef]

28. Macnab, R.M. How bacteria assemble flagella. Annu. Rev. Microbiol. 2003, 57, 77-100. [CrossRef]

29. Looney, W.J.; Narita, M.; Mühlemann, K. Stenotrophomonas maltophilia: An emerging opportunist human pathogen. Lancet Infect. Dis. 2009, 9, 312-323. [CrossRef]

30. Gajdacs, M.; Urban, E. A 10-year single-center expreience on Stenotrophomonas maltophilia resistotyping in Szeged, Hungary. Eur. J. Microbiol. Immunol. 2020, 10, 91-97. [CrossRef]

31. Gil-Gil, T.; Martínez, J.L.; Blanco, P. Mechanisms of antimicrobial resistance in Stenotrophomonas maltophilia: A review of current knowledge. Expert Rev. Anti-Infect. Ther. 2020, 18, 335-347. [CrossRef]

32. Biagi, M.; Vialichka, A.; Jurkovic, M.; Wu, T.; Shajee, A.; Lee, M.; Patel, S.; Mendes, R.E.; Wenzler, E. Actvitiy of cefiderocol alone and in combination with levofloxacin, minocycline, polymyxin B or trimethoprim-sulfamethoxazole against multidrug-resistant Stenotrophomonas maltophilia. Antimicrob. Agents Chemother. 2020, 64, e00559-20.

33. Huang, Y.W.; Huang, H.H.; Huang, K.H.; Chen, W.C.; Lin, Y.T.; Hsu, C.C.; Yang, T.C. AmpI functions as an iron exporter to alleviate $\beta$-lactam-mediated reactive oxygen species stress in Stenotrophomonas maltophilia. Antimicrob. Agents Chemother. 2019, 63, e02467-18. [CrossRef] [PubMed]

34. Xu, G.; Tang, X.; Shang, X.; Li, Y.; Wang, J.; Yue, J.; Li, Y. Identification of immunogenic outer membrane proteins and evaluation of their protective efficacy against Stenotrophomonas maltophilia. BMC Infect. Dis. 2018, 18, 347. [CrossRef] [PubMed]

35. Li, Y.; Tang, X.; Zhao, Z.; Wang, H.; Wang, X.; Shang, X.; Liu, P.; Kou, Z.; Jiang, Y.; Li, Y. Intranasal immunization with recombinant outer membrane protein A induces protective immune response aginst Stenotrophomonas maltophilia infection. PLoS ONE 2019, 14, e0214596.

36. Yang, T.C.; Huang, Y.W.; Hu, R.M.; Huang, S.C.; Lin, Y.T. AmpDI is involved in expression of the chromosomal L1 and L2 $\beta$-lactamases of Stenotrophomonas maltophilia. Antimicrob. Agents Chemother. 2009, 53, 2902-2907. [CrossRef]

37. Li, L.H.; Zhang, M.S.; Wu, C.J.; Lin, Y.T.; Yang, T.C. Overexpression of SmeGH contributes to the acquired MDR of Stenotrophomonas maltophilia. J. Antimicrob. Chemother. 2019, 74, 2225-2229. [CrossRef]

38. Lin, C.W.; Huang, Y.W.; Hu, R.M.; Chiang, K.H.; Yang, T.C. The role of AmpR in regulation of L1 and L2 $\beta$-lactamases in Stenotrophomonas maltophilia. Res. Microbiol. 2009, 160, 152-158. [CrossRef]

39. Lin, Y.T.; Huang, Y.W.; Chen, S.J.; Chang, C.W.; Yang, T.C. The SmeYZ efflux pump of Stenotrophomonas maltophilia contributes to drug resistance, virulence-related characteristics, and virulence in mice. Antimicrob. Agents Chemother. 2015, 59, 4067-4073. [CrossRef]

40. Crossman, L.C.; Gould, V.C.; Dow, J.M.; Vernikos, G.S.; Okazaki, A.; Sebaihia, M.; Saunders, D.; Arrowsmith, C.; Carver, T.; Peters, N.; et al. The complete genome, comparative and functional analysis of Stenotrophomonas maltophilia reveals an organism heavily shielded by drug resistance determinants. Genome Biol. 2008, 9, R74. [CrossRef]

41. Huang, H.H.; Chen, W.C.; Lin, C.W.; Lin, Y.T.; Ning, H.C.; Chang, Y.C.; Yang, T.C. Relationship of the CreBC two-component regulatory system and inner membrane protein CreD with swimming motility in Stenotrophomonas maltophilia. PLoS ONE 2017, 12, e0174704. [CrossRef]

42. Chen, C.H.; Huang, C.C.; Chung, T.C.; Hu, R.M.; Huang, Y.W.; Yang, T.C. Contribution of resistance-nodulation-division efflux pump operon smeU1-V-W-U2-X to multidrug resistance of Stenotrophomonas maltophilia. Antimicrob. Agents Chemother. 2011, 55, 5826-5833. [CrossRef]

43. Livak, K.J.; Schmittgen, T.D. Analysis of relative gene expression data using real-time quantitative PCR and the 2-(delta delta C(T)) method. Methods 2001, 25, 402-408. [CrossRef]

44. Hu, R.M.; Huang, K.J.; Wu, L.T.; Hsiao, Y.J.; Yang, T.C. Induction of L1 and L2 $\beta$-lactamases of Stenotrophomonas maltophilia. Antimicrob. Agents Chemother. 2008, 52, 1198-1200. [CrossRef]

45. de Oliveira-Garcia, D.; Dall'Agnol, M.; Rosales, M.; Azzuz, A.C.; Martinez, M.B.; Girón, J.A. Characterization of flagella produced by clinical strains of Stenotrophomonas maltophilia. Emerg. Infect. Dis. 2002, 8, 918-923. [CrossRef]

46. Ritchings, B.W.; Almira, E.C.; Lory, S.; Ramphal, R. Cloning and phenotypic characterization of fleS and fleR, new response regulators of Pseudomonas aeruginosa which regulate motility and adhesion to mucin. Infect. Immun. 1995, 63, 4868-4876. [CrossRef] [PubMed]

47. Josenhans, C.; Suerbaum, S. The role of motility as a virulence factor in bacteria. Int. J. Med. Microbiol. 2002, 291, 605-614. [CrossRef]

48. Spangenberg, C.; Heuer, T.; Bürger, C.; Tümmler, B. Genetic diversity of flagellins of Pseudomonas aeruginosa. FEBS Lett. 1996, 396, 213-217. [CrossRef]

49. Jyot, J.; Dasgupta, N.; Ramphal, R. FleQ, the major flagellar gene regulator in Pseudomonas aeruginosa, binds to enhancer sites located either upstream or atypically downstream of the RpoN binding site. J. Bacteriol. 2002, 184, 5251-5260. [CrossRef] [PubMed] 
50. Starnbach, M.N.; Lory, S. The fliA ( $r p o F)$ gene of Pseudomonas aeruginosa encodes an alternative sigma factor required for flagellin synthesis. Mol. Microbiol. 1992, 6, 459-469. [CrossRef] [PubMed]

51. Arora, S.K.; Ritchings, B.W.; Almira, E.C.; Lory, S.; Ramphal, R. A transcriptional activator, FleQ, regulates mucin adhesion and flagellar gene expression in Pseudomonas aeruginosa in a cascade manner. J. Bacteriol. 1997, 179, 5574-5581. [CrossRef]

52. Meng, X.; Liu, X.; Zhang, L.; Hou, B.; Li, B.; Tan, C.; Li, Z.; Zhou, R.; Li, S. Virulence characteristics of extraintestinal pathogenic Escherichia coli deletion of gene encoding the outer membrane protein X. J. Vet. Med. Sci. 2016, 78, 1261-1267. [CrossRef]

53. Martinez, R.M.; Dharmasena, M.N.; Kirn, T.J.; Taylor, R.K. Characterization of two outer membrane proteins, FlgO and FlgP, that influence vibrio cholerae motility. J. Bacteriol. 2009, 191, 5669-5679. [CrossRef] [PubMed]

54. Bari, W.; Lee, K.M.; Yoon, S.S. Structural and functional importance of outer membrane proteins in Vibrio cholerae flagellum. J. Microbiol. 2012, 50, 631-637. [CrossRef]

55. Yang, B.; Zhang, D.; Wu, T.; Zhang, Z.; Raza, S.H.A.; Schreurs, N.; Zhang, L.; Yang, G.; Wang, C.; Qian, A.; et al. Maltoporin (LamB protein) contributes to the virulence and adhesion of Aeromonas veronii TH0426. J. Fish. Dis. 2019, 42, 379-389. [CrossRef] [PubMed]

56. Mitchell, A.M.; Silhavy, T.J. Envelope stress response: Balancing damage repair and toxicity. Nat. Rev. Microbiol. 2019, 17, 417-418. [CrossRef] [PubMed]

57. Manoil, C.; Rosenbusch, J.P. Conjugation-deficient mutants of Escherichia coli distinguish classes of functions of the outer membrane OmpA protein. Mol. Gen. Genet. 1982, 187, 148-156. [CrossRef] [PubMed]

58. Klimke, W.A.; Rypien, C.D.; Klinger, B.; Kennedy, R.A.; Rodriguez-Maillard, J.M.; Frost, L.S. The mating pair stabilization protein, TraN, of the F plasmid is an outer-membrane protein with two regions that are important for its function in conjugation. Microbiology 2005, 151, 3527-3540. [CrossRef]

59. Lerminiaux, N.A.; Cameron, A.D.S. Horizontal transfer of antibiotic resistance genes in clinical environments. Can. J. Microbiol. 2019, 65, 34-44. [CrossRef]

60. Graf, F.E.; Palm, M.; Warringer, J.; Farewell, A. Inhibiting conjugation as a tool in the fight against antibiotic resistance. Drug Dev. Res. 2019, 80, 19-23. [CrossRef]

61. Gajdacs, M.; Urban, E. Prevalence and antibiotic resistance of Stenotrophomonas maltophilia in respiratory tract samples: A 10-year epidemiological snapshot. Health Serv. Res. Manag. Epidemiol. 2019, 6, 2333392819870774. [CrossRef] [PubMed] 